\title{
Durability properties of alkali pozzolan cement (APC)
}

\author{
Chandana Kulasuriya ${ }^{1}$, W.P.S. Dias ${ }^{2 *}$ and Vanissorn Vimonsatit ${ }^{1}$ \\ ${ }^{1}$ Department of Civil Engineering, Curtin University, Perth, Australia. \\ ${ }^{2}$ Department of Civil Engineering, Faculty of Engineering, University of Moratuwa, Katubedda, Moratuwa.
}

Submitted: 29 January 2018; Revised: 31 August 2018; Accepted: 28 September 2018

\begin{abstract}
This paper compares the durability properties of alkali pozzolan cement (APC) with high volume fly ash (HVFA) cement and ordinary Portland cement (OPC). The susceptibility to durability issues was investigated through the water absorption test using 28-day-old samples. Durability against chemical attacks was investigated through sulphuric acid attack, chloride ion penetration and carbonation tests on 1-year-old samples. The results indicated that APC occupies a median position in relation to OPC and HVFA, having greater resistance than HVFA for water absorption and carbonation, and greater resistance than OPC for sulphuric acid attack and chloride ion penetration. Chemical and microstructural reasons for the above behaviours are presented. A key index of durability performance is the free calcium hydroxide available and/or generated during cement hydration and durability exposure.
\end{abstract}

Keywords: Calcium hydroxide, carbonation, chloride ion penetration, sulphuric acid attack, water absorption.

\section{INTRODUCTION}

Alkali pozzolan cement, developed previously by the authors (Kulasuriya et al., 2014), is an alternative cement comprising non-hazardous chemicals that can be cured under normal conditions and stored as a dry powder. The term 'alkali pozzolan cement' is used since the research was started with a preliminary cementitious mixture comprising alkali and pozzolanic materials, and the abbreviated form 'APC' is used throughout this paper. We have argued that alternative cements such as APC are very relevant and important in the context of environmental sustainability through reduced usage of ordinary Portland cement (OPC); especially since the strength development of APC was shown to be promising even with respect to OPC (Kulasuriya et al., 2014). This paper focuses on the durability properties, while a summary of compressive strength results is also included. Resistance to carbonation, sulphuric acid attack and chloride ion penetration were explored, as well as water absorption, which gives an indication about the porosity and penetrability of the hydrated cement.

APC can be seen as a hybrid cement, which consists of pozzolans, alkali materials, activators and OPC (Fernandez-Jimenez et al., 2013; Donatello et al., 2014). The main distinctive feature of APC is that it is in the form of a dry cement powder that uses only nonhazardous materials (Kulasuriya et al., 2014). Research on durability properties of hybrid cements is extremely limited, thus justifying the need for this research. Most explorations of hybrid cements have been confined to strength properties. However, Fernandez-Jimenez et al. (2013) investigated the resistance to hydrochloric acid, sodium sulphate and seawater of a hybrid cement derived from blast furnace slag and zinc slag and compared it to the resistance of OPC. Donatello et al. (2014) also investigated the resistance of hybrid alkaline coal fly ash cement to the same three aggressive agents and compared its performance to a sulphate resistant cement. Donetello et al. (2013) have substantiated their phenomenological findings with microstructural studies using XRD, FTIR spectroscopy and SEM/EDX.

\footnotetext{
*Corresponding author (priyan@uom.lk; (iD http://orcid.org/0000-0003-0333-7189)
} 
The first aim in this research was to investigate the susceptibility to durability issues through water absorption tests using 28-day-old samples; such samples were considered old enough to reflect the time dependent changes in cement properties but also young enough to accentuate the differences between mixtures. The second aim was to investigate durability issues due to chemical attacks using more mature year-old samples; these may be more representative of service conditions. The third aim was to determine the sensitivity of durability properties to changes in water-cement $(\mathrm{w} / \mathrm{c}$ ) ratio (from 0.3 to 0.4 ). The above durability properties of APC were compared with those of high volume fly ash (HVFA) cement, since HVFA is another way of combining low percentages of OPC with high percentages of fly ash. OPC was investigated as the reference, since APC was developed as an alternative to OPC.

\section{METHODOLOGY}

\section{Raw materials}

The pozzolanic material used in the mixtures was class $\mathrm{F}$ fly ash, which had $51.6 \% \mathrm{SiO}_{2}, 27.6 \% \mathrm{Al}_{2} \mathrm{O}_{3}$ and $1.6 \% \mathrm{CaO}$. The remaining $19.2 \%$ contained mainly $\mathrm{Fe}$ compounds. Its fineness was found to be $340 \mathrm{~m}^{2} \mathrm{~kg}^{-1}$. The alkali material used was a fine lime powder available in the market and derived from quicklime via grinding and slaking. Hence it can be considered as a mixture of quicklime and hydrated lime. Its fineness was such that typical residues on $250 \mu \mathrm{m}$ and $75 \mu \mathrm{m}$ sieves were $0.4 \%$ and $6 \%$, respectively. The $\mathrm{CaO}$ content [whether as $\mathrm{CaO}$ or $\mathrm{Ca}(\mathrm{OH})_{2}$ ] was $56.5 \%$. The lime powder also contained small amounts of $\mathrm{MgO}$ (3.6\%), $\mathrm{SiO}_{2}(2.3 \%)$ and $\mathrm{Al}_{2} \mathrm{O}_{3}(0.5 \%)$. The remaining $37.1 \%$ contained mainly moisture and compounds of $\mathrm{Fe}, \mathrm{K}, \mathrm{Na}, \mathrm{S}$ and $\mathrm{Sr}$ in small percentages. The OPC used was the normal type general purpose OPC available in Western Australia, which has a minimum compressive strength of $40 \mathrm{MPa}$ at 28 days as per AS3972 (Standards Australia, 2010). It typically contains $63.6 \% \mathrm{CaO}, 21.1 \% \mathrm{SiO}_{2}$ and $4.7 \% \mathrm{Al}_{2} \mathrm{O}_{3}$; the remaining $10.6 \%$ contains mainly $\mathrm{Fe}_{2} \mathrm{O}_{3}, \mathrm{MgO}$ and $\mathrm{SO}_{3}$. Its fineness was determined as $370 \mathrm{~m}^{2} \mathrm{~kg}^{-1}$. The activating chemical used was a fine powder form of $\mathrm{Na}_{2} \mathrm{SO}_{4}$.

\section{Practical, comparable and reference mixtures}

The 'practical APC' mixture that emerged from the previous research (Kulasuriya et al., 2014) contains APC70, sodium sulphate $\left(\mathrm{Na}_{2} \mathrm{SO}_{4}\right)$ and $\mathrm{OPC}$, the formula of which is $70 \%$ of $\left(95 \% \mathrm{APC} 70+5 \% \mathrm{Na}_{2} \mathrm{SO}_{4}\right)+$ $30 \%$ of OPC; where APC70 $=70 \%$ fly ash $+30 \%$ lime. The other APC mixtures investigated contained APC60 and APC80. In the previous research (Kulasuriya et al., 2014), the development of mixtures started with pure APC70, then proceeded by adding $\mathrm{Na}_{2} \mathrm{SO}_{4}$ followed by adding OPC. Hence, the formulation of mixtures also developed in the sequence reflected in the definition of the above formulation. The same style of formulation is used to describe mixtures in this paper, since this is a continuation of the previous research. $\mathrm{Na}_{2} \mathrm{SO}_{4}$ is used since it has been found to be a good alkaline increasing activator (Kulasuriya et al., 2014). A mixture containing $70 \%$ fly ash and $30 \%$ OPC was used as the comparable mixture, because the percentage of OPC used to design all the practical APC mixtures was also $30 \%$. Moreover, $70 \%$ is realistically the largest replacement percentage of low calcium fly ash (class F fly ash) that can be used in high volume fly ash (HVFA) mixtures (e.g. Qian et al., 2001). The mixture containing $100 \%$ OPC was used as the reference mixture. Accordingly, the compositions of dry cement powders were chosen as below:

Notation: $\mathrm{APCk}=\mathrm{k} \%$ fly ash $+(100-\mathrm{k}) \%$ lime

APC mixtures

$\mathrm{L}=70 \%\left(95 \% \mathrm{APC} 60+5 \% \mathrm{Na}_{2} \mathrm{SO}_{4}\right)+30 \% \mathrm{OPC}$

$\mathrm{M}=70 \%\left(95 \% \mathrm{APC} 70+5 \% \mathrm{Na}_{2} \mathrm{SO}_{4}\right)+30 \% \mathrm{OPC}$

$\mathrm{N}=70 \%\left(95 \% \mathrm{APC} 80+5 \% \mathrm{Na}_{2} \mathrm{SO}_{4}\right)+30 \%$ OPC

HVFA mixture

$\mathrm{C}=70 \%$ fly ash $+30 \%$ OPC

OPC mixture

$\mathrm{R}=100 \% \mathrm{OPC}$

The above dry cement powders were mixed with water using w/c ratios of 0.3 and 0.4 , resulting in two pastes from each cement and denoted by suffixes 3 and 4 . For example, the pastes prepared from cement $\mathrm{M}$ with $\mathrm{w} / \mathrm{c}=0.3$ and 0.4 were denoted M3 and M4, respectively.

Although the focus of this paper is on durability, Table 1 summarises the 28-day compressive strength results of the above mixtures (Kulasuriya et al., 2014; Kulasuriya, 2015). As expected all results for the $0.4 \mathrm{w} / \mathrm{c}$ ratio are less than the corresponding ones for the $0.3 \mathrm{w} / \mathrm{c}$ ratio. Also, the ranking of strength can be denoted as OPC $>$ APC $>$ HVFA where the main comparison is concerned. When the finer comparison between the APC mixtures is concerned, we can denote the ranking as $\mathrm{L}>\mathrm{M}>\mathrm{N}$ for the $0.3 \mathrm{w} / \mathrm{c}$ mixtures - i.e. the strength is higher when the lime percentage is higher; however, no clear trend can be seen for the $0.4 \mathrm{w} / \mathrm{c}$ mixtures. 
Table 1: Summary of strength results at 28 days

\begin{tabular}{cccc}
\hline Mixture & Description & Compressive \\
& Composition & w/c & strength at \\
& & ratio & 28 days (MPa) \\
\hline
\end{tabular}

\begin{tabular}{|c|c|c|c|}
\hline \multicolumn{4}{|c|}{ Practical APC mixtures } \\
\hline L3 & $70 \%\left(95 \%\right.$ APC60 $\left.+5 \% \mathrm{Na}_{2} \mathrm{SO}_{4}\right)+30 \%$ OPC & 0.3 & 50 \\
\hline L4 & $70 \%\left(95 \%\right.$ APC60 $\left.+5 \% \mathrm{Na}_{2} \mathrm{SO}_{4}\right)+30 \% \mathrm{OPC}$ & 0.4 & 26 \\
\hline M3 & $70 \%\left(95 \% \mathrm{APC} 70+5 \% \mathrm{Na}_{2} \mathrm{SO}_{4}\right)+30 \% \mathrm{OPC}$ & 0.3 & 46 \\
\hline M4 & $70 \%\left(95 \% \mathrm{APC} 70+5 \% \mathrm{Na}_{2} \mathrm{SO}_{4}\right)+30 \% \mathrm{OPC}$ & 0.4 & 32 \\
\hline N3 & $70 \%\left(95 \%\right.$ APC $\left.80+5 \% \mathrm{Na}_{2} \mathrm{SO}_{4}\right)+30 \% \mathrm{OPC}$ & 0.3 & 42 \\
\hline N4 & $70 \%\left(95 \% \mathrm{APC} 80+5 \% \mathrm{Na}_{2} \mathrm{SO}_{4}\right)+30 \% \mathrm{OPC}$ & 0.4 & 28 \\
\hline \multicolumn{4}{|c|}{ Comparable HVFA mixtures } \\
\hline $\mathrm{C} 3$ & $70 \% \mathrm{FA}+30 \% \mathrm{OPC}$ & 0.3 & 24 \\
\hline $\mathrm{C} 4$ & $70 \% \mathrm{FA}+30 \% \mathrm{OPC}$ & 0.4 & 13 \\
\hline \multicolumn{4}{|c|}{ Reference OPC mixtures } \\
\hline R3 & $100 \%$ OPC & 0.3 & 57 \\
\hline R4 & $100 \%$ OPC & 0.4 & 40 \\
\hline
\end{tabular}

$\mathrm{APCk}=\mathrm{k} \%$ pozzolan $+(100-\mathrm{k}) \%$ lime

Dry cementitious mixtures are identified by letters L, M, N, C and R; suffixes 3 and 4 are added to identify the pastes prepared with $\mathrm{w} / \mathrm{c}=0.3$ and $\mathrm{w} / \mathrm{c}=0.4$.

\section{Experimental procedures}

The cement pastes were prepared by mixing dry cementitious powder with water, keeping the water to cementitious mixture ratios either at 0.3 or 0.4 by weight. A number of specimen sets of size $50 \times 50 \times 50 \mathrm{~mm}$ were made from each mixture and each set was cured under one of two conditions. Samples cured in air under controlled conditions of $20-25{ }^{\circ} \mathrm{C}$ and $70-75 \% \mathrm{RH}$ are described as air cured. Those cured for $15 \mathrm{~h}$ under the above conditions prior to demoulding, followed by water curing until testing are described as water cured. Air cured samples were used to test water absorption, sulphuric acid attack and carbonation, since dry conditions (that could be also experienced in practice) would be more critical and also accentuate differences across mixtures. Wet cured samples were used to test sodium chloride penetration, because concretes in marine chloride environments are also likely to be wet.

Three samples from each mixture were used to obtain average values. During the durability tests, specimens were kept on specimen holders, the platforms of which were made of a square net. The surface area of the specimen in contact with the net was negligible, thus allowing the relevant fluid to be in contact with specimens without any obstruction.

\section{Water absorption test}

In designing the water absorption test, related literature on water absorption of concrete, mortar and masonry units was used as a guide (ASTM C140), although the samples used in this research were of cement paste. Since the objective of performing water absorption testing was to characterise porosity and penetrability, a test method where all six surfaces are exposed to water was considered more suitable than those where some surfaces are sealed (Dias, 2000). Samples were immersed in water at $20-25^{\circ} \mathrm{C}$, such that the top surface was at least $150 \mathrm{~mm}$ below the water surface. The saturated surface dried weights $\left(W_{s}\right)$ were recorded after immersing the samples for $24 \mathrm{~h}$. Next the samples were dried in an oven at $105^{\circ} \mathrm{C}$ for not less than $24 \mathrm{~h}$ until the weight did not decrease by more than $0.2 \%$ in $2 \mathrm{~h}$, after which dry weights $\left(W_{d}\right)$ were recorded. 
Water absorption was determined as:

Water absorption $(\%)=\frac{W_{s}-W_{d}}{W_{d}} * 100 \%$

\section{Sulphuric acid attack test}

In designing the sulphuric acid attack test, literature on acid attack of concrete and mortar were used as a guide (ASTM C267). Air cured specimens were immersed in $3 \% \mathrm{H}_{2} \mathrm{SO}_{4}$ acid (cf. Ghrici et al., 2007) for $16 \mathrm{wks}$. Since the acid gets diluted and contaminated, it was replenished every 4 wks. A ratio of 1:5 between volumes of specimens and acid (cf.1:4 in Wallah \& Rangan, 2006) was used in order to fully immerse the specimen. Before immersing the samples, the dry weights $\left(W_{d}\right)$ were measured. After immersion, weights $\left(W_{i}\right)$ were measured at $2 \mathrm{~h}, 1 \mathrm{~d}, 3 \mathrm{ds}$ and $7 \mathrm{ds}$, and after that every $7 \mathrm{ds}$ up to $112 \mathrm{ds}$. The acid attack index for each specimen was obtained as the percentage weight change (e.g. Ghrici et al., 2007):

Weight change $(\%)=\frac{W_{i}-W_{d}}{W_{d}} * 100 \%$

\section{Sodium chloride penetration test}

It has been argued that permeability and chloride ponding tests are controversial for pozzolanic mixtures (Ryan, 1999). Hence, a submersion approach was adopted. Water cured samples were immersed in $5 \% \mathrm{NaCl}$ solution (Dias et al., 2008) for 12 wks (i.e. around 3 months). The $\mathrm{NaCl}$ solution was also replenished every 4 wks as in the acid attack test. The ratio between volumes of specimens to the solution was taken as 1:4 (Wallah \& Rangan, 2006). After 12 wks of immersion, samples were taken out of the solution and split into two over the trowelled face, so that the resulting cross section was bounded by the specimen's bottom face, two side faces and top (or trowelled) face. After that, $0.1 \mathrm{~N} \mathrm{AgNO}_{3}$ solution was applied on the split surfaces (Otsuki et al., 1993). In the region of chloride penetration, $\mathrm{AgNO}_{3}$ reacted with chloride to form silver-white coloured $\mathrm{AgCl}$. The depth of penetration was determined by taking 4 measurements from each face other than the trowelled face (to avoid inconsistencies due to variations in trowelling). The mean depth for each sample was computed from these 12 measurements.

\section{Carbonation test}

Carbonation resistance was investigated through an accelerated carbonation test. Inside the carbonation chamber the temperature was around $20-25{ }^{\circ} \mathrm{C}$ and relative humidity was around $65 \%$, when carbonation is likely to be rapid (Gonen \& Yazicioglu, 2007).
Multiple trays of saturated $\mathrm{NaNO}_{2}$ solution were kept inside the chamber to control the relative humidity. The concentration in the test chamber was set to $3 \% \mathrm{CO}_{2}$, which is 100 times that of the natural $\mathrm{CO}_{2}$ concentration in the environment $\left(5 \% \mathrm{CO}_{2}\right.$ used in Atis, 2003 and $1 \%$ in Pipilikaki and Katsioti, 2009). Two sets of air cured specimens from each mixture were kept in the carbonation chamber. One set was taken out after 4 wks and the other after 12 wks. The specimens were split into two over the trowelled face, so that the cross section was bounded by the bottom, two sides and top (or trowelled) faces. A 1\% phenolphthalein solution was applied on freshly split sections. The region that remained colourless was taken as the carbonated region. The depth of carbonation was determined by taking 4 measurements from each face other than the trowelled face, and the mean depth for each sample was computed from these 12 measurements.

\section{RESULTS AND DISCUSSION}

In addition to comparing the various durability parameters across mixtures, the sensitivity of those parameters with respect to $\mathrm{w} / \mathrm{c}$ ratio was also computed based on a sensitivity index, defined as below;

Sensitivity index $(S I)=\frac{X_{0.4}-X_{0.3}}{X_{0.3}}=\frac{X_{0.4}}{X_{0.3}}-1$

Here,

$X_{0.3}$ - value of the parameter considered of samples having $\mathrm{w} / \mathrm{c}=0.3$

$X_{0.4}$ - value of the parameter considered of samples having $\mathrm{w} / \mathrm{c}=0.4$

$X$ can be water absorption percentage, chloride ion penetration depth or carbonation depth.

The mixtures were compared on the basis of 2 separate groups, namely the $\mathrm{M}-\mathrm{C}-\mathrm{R}$ grouping to compare the APC mixture $\mathrm{M}$ with comparable mixture $\mathrm{C}$ (HVFA) and reference mixture R (OPC); and the L-M-N grouping to compare the APC mixture $\mathrm{M}$ with its neighbouring APC mixtures $\mathrm{L}$ and $\mathrm{N}$. When describing results, the durations of 4, 12 and 16 weeks are described as 1, 3 and 4 months, respectively.

\section{Water absorption}

Water absorption percentages are presented in Figure 1. According to the figure it is very clear that for a given mixture, water absorption is higher in specimens with $\mathrm{w} / \mathrm{c}=0.4$ than those with $\mathrm{w} / \mathrm{c}=0.3$ because of greater porosity in the former. Figure 1(a) also indicates that for 
a given w/c ratio, water absorption of APC mixture $M$ is greater than that of OPC mixture R but less than that of HVFA mixture $\mathrm{C}$. The reason is that the degree of pore structure filling by hydrated products decreases from OPC through APC to HVFA. Hence, the resistance to water absorption would also decrease from OPC through APC to HVFA. According to Figure 1(b), for a given w/c ratio, the water absorption of mixture $\mathrm{L}$ is slightly greater than that of both $\mathrm{M}$ and $\mathrm{N}$ mixtures. The reason could be that mixture $\mathrm{L}$ has the greatest proportion of added lime; and unreacted lime could be leached away when samples are immersed in water, thus making samples more porous. Hence, resistance to water absorption is least in mixture L in the L-M-N grouping.

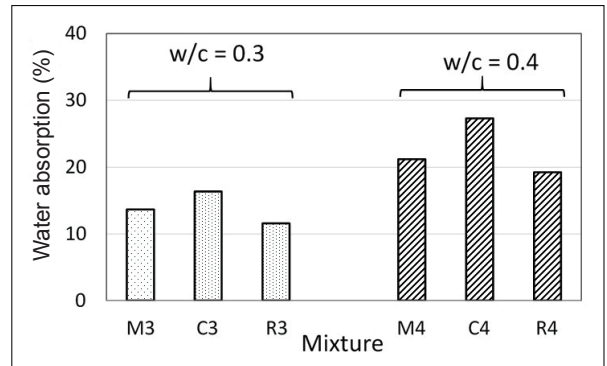

(a) Water absorption: M-C-R grouping

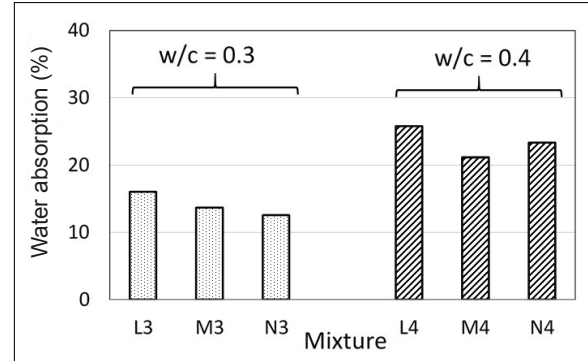

(b) Water absorption: L-M-N grouping

Figure 1: Percentage of water absorption

Sensitivity indices of the mixtures are as follows: L- 0.61 , $\mathrm{M}-0.55, \mathrm{~N}-0.86, \mathrm{C}-0.67$ and $\mathrm{R}-0.66$. Hence, the sensitivity to w/c of APC mixture M is slightly less than that of HVFA mixture $\mathrm{C}$ and OPC mixture R. It may be that part of the extra water is used to convert any $\mathrm{CaO}$ in added lime into $\mathrm{Ca}(\mathrm{OH})_{2}$, rather than to increase the porosity. Thus, the robustness (which is the opposite of sensitivity) of APC is slightly better than that of OPC and HVFA. The sensitivity to $\mathrm{w} / \mathrm{c}$ of APC mixture $\mathrm{N}$ is clearly higher than that of APC mixtures L and M. Mixture N has the least quantity of lime among APC mixtures, hence needs a smaller amount of water than others for hydration. Therefore, excess water would increase the porosity rather than contributing to hydration. Thus, the robustness of mixtures $\mathrm{L}$ and $\mathrm{M}$ are slightly better than that of $\mathrm{N}$.

\section{Sulphuric acid attack}

Percentage weight changes are presented in Figure 2 as a function of time. Solid lines denote $\mathrm{w} / \mathrm{c}=0.3$ mixtures, and broken lines denote $\mathrm{w} / \mathrm{c}=0.4$ mixtures. The photographs of samples taken at immersion and 112 days after immersion of OPC mixture R3, HVFA mixture $\mathrm{C} 3$ and $\mathrm{APC}$ mixture M3 in sulphuric acid are shown in Figure 3.

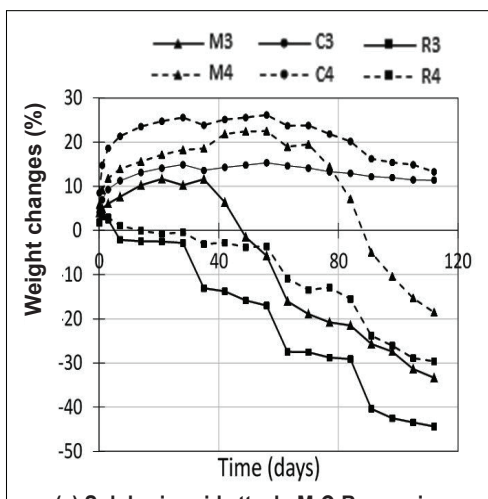

(a) Sulphuric acid attack: M-C-R grouping

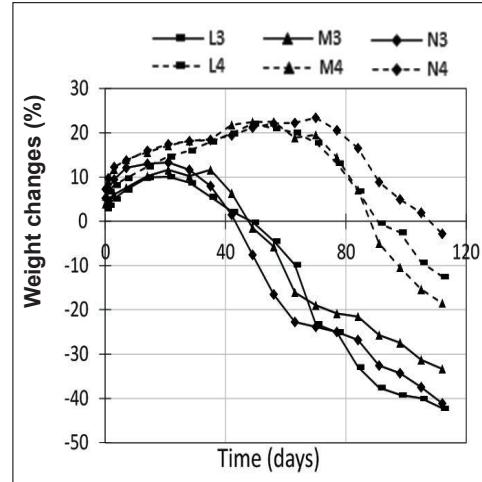

(b) Sulphuric acid attack: L-M-N grouping

Figure 2: Percentage weight changes due to sulphuric acid attack 


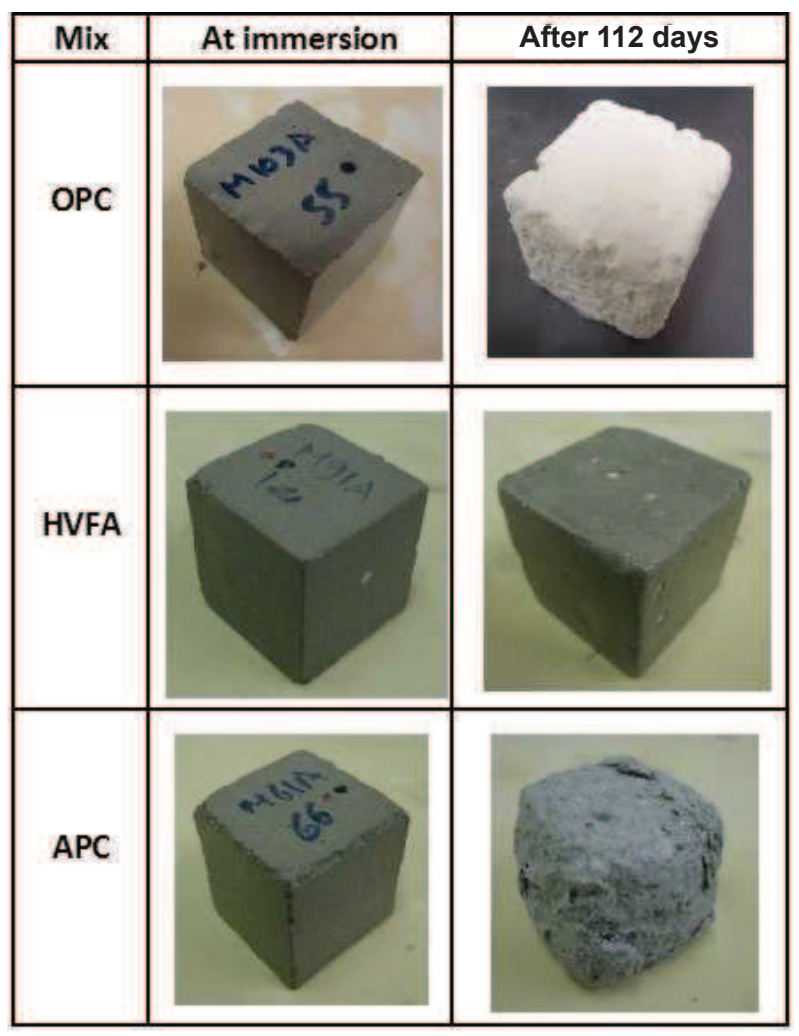

Figure 3: Sulphuric acid attack on samples of OPC, HVFA and APC

Figure 2(a) indicates that for a given $\mathrm{w} / \mathrm{c}$ ratio at a given time, weight losses generally decrease from OPC through APC to HVFA. This is reflected in Figure 3 as well. Sulphuric acid attack on hydrated cement occurs in two stages, i.e. formation of gypsum and formation of ettringite (O'Connell et al., 2010). In the first stage $\mathrm{H}_{2} \mathrm{SO}_{4}$ reacts with $\mathrm{Ca}(\mathrm{OH})_{2}$ and $\mathrm{C}-\mathrm{S}-\mathrm{H}$ to form gypsum $\left(\mathrm{CaSO}_{4} \cdot 2 \mathrm{H}_{2} \mathrm{O}\right)$. In the second stage, the newly formed gypsum reacts with hydrated tricalcium aluminates $\left(\mathrm{C}_{3} \mathrm{~A} . \mathrm{H}_{12}\right)$ to form ettringite $\left(\mathrm{C}_{3} \mathrm{~A} .3 \mathrm{C} \overline{\mathrm{S}} . \mathrm{H}_{32}\right)$ (Mondal et al., 2011). The volume of the ettringite is much greater than the total volume of initial compounds, hence significant volume expansion occurs as a result of these processes (Monteny et al., 2000). The increase in volume can lead to cracking and/or peeling of samples that lead to weight losses. Furthermore, the formation of $\mathrm{CaSO}_{4}$ would make the samples soft (Attogbe \& Rizkalla, 1988), and separation of soft parts also leads to weight losses. Hence, damage to a sample depends on the quantity of $\mathrm{C}_{3} \mathrm{~A} \cdot \mathrm{H}_{12}$, the quantity of free $\mathrm{Ca}(\mathrm{OH})_{2}$ and voids available in the sample for ettringite to expand into. The quantity of $\mathrm{C}_{3} \mathrm{~A}$. $\mathrm{H}_{12}$ in the sample depends on the quantity of OPC in the mixture. OPC samples have the greatest quantity of $\mathrm{C}_{3} \mathrm{~A}$. $\mathrm{H}_{12}$ while APC and HVFA have $\mathrm{C}_{3} \mathrm{~A} \cdot \mathrm{H}_{12}$ only around
$30 \%$ of OPC's quantity, since APC and HVFA have only $30 \%$ OPC as described previously. Thus, the quantity of ettringite formed would be greatest in OPC. The quantity of free $\mathrm{Ca}(\mathrm{OH})_{2}$ would be very much less in HVFA samples than in OPC and APC samples, since the limited $\mathrm{Ca}(\mathrm{OH})_{2}$ released during the OPC hydration process would be consumed in pozzolanic reactions. The voids available in samples also increase from OPC through APC to HVFA. Thus, the weight loss of the samples due to damages decreases from OPC through APC to HVFA; i.e. the resistance to sulphuric acid attack increases in the same sequence. Another significant feature that can be noticed is the marked weight loss during the periods from 28-35, 56-63 and 84-91 days in OPC mixtures R3 and R4. This is due to replenishment of acid at 28, 48 and 84 days. The results of Fernandez-Jimenez et al., (2013) are also consistent with the above findings; the resistance of their hybrid cement specimens to both $\mathrm{HCl}$ attack and $\mathrm{Na}_{2} \mathrm{SO}_{4}$ exposure was better than that of the corresponding OPC ones.

The results of the present study also indicate that for a given mixture, the weight loss reduces when the $\mathrm{w} / \mathrm{c}$ ratio increases. When the $\mathrm{w} / \mathrm{c}$ ratio increases, samples become more porous, resulting in more voids for the ettringite to expand into. Further, for a given mixture when the w/c ratio increases, the OPC content per volume decreases; hence contents of $\mathrm{C}_{3} \mathrm{~S}, \mathrm{C}_{2} \mathrm{~S}$ and $\mathrm{C}_{3} \mathrm{~A}$ per volume also decrease. As a result, hydrated products such as $\mathrm{C}_{3} \mathrm{~A} \cdot \mathrm{H}_{12}$, $\mathrm{C}-\mathrm{S}-\mathrm{H}$ and $\mathrm{Ca}(\mathrm{OH})_{2}$ formed during hydration processes decrease, as does the subsequent formation of gypsum and ettringite. Accordingly, when the $\mathrm{w} / \mathrm{c}$ ratio increases, the damage to samples decreases.

Figure 2(b) presents the weight loss curves for the different APC mixtures L, M and N. For a given w/c ratio, weight losses are similar throughout the period of exposure. Since APC mixtures L, M and N have $30 \%$ OPC, they would have the same quantity of $\mathrm{C}_{3} \mathrm{~A} \cdot \mathrm{H}_{12}$. Hence, the subsequent formation of ettringite and the resulting damage would be approximately the same; thus the resistance to sulphuric acid attack is also similar in L, $\mathrm{M}$ and $\mathrm{N}$ mixtures. These results also indicate that for a given mixture, the weight loss due to damage reduces as porosity increases with the $\mathrm{w} / \mathrm{c}$ ratio.

Sensitivity to w/c ratio of sulphuric acid attack was not explored using the sensitivity index described before, mainly because an increase in w/c ratio is beneficial as opposed to detrimental. However, it should be noted that the curves of mixtures $\mathrm{M}$ and $\mathrm{R}$ shift upwards significantly when the w/c ratio is increased from 0.3 to 0.4 ; but this is not the case for mixture $\mathrm{C}$ as shown in Figure 2(a). 
The relatively large porosity of C3 samples would be adequate to accommodate the limited ettringite formed, and hence a further increase of porosity as a result of $\mathrm{w} / \mathrm{c}$ ratio increase would not help much. However, in the cases of APC and OPC, an increase of w/c ratio would result in much needed extra pore space for the ettringite to occupy, and hence their sensitivities to w/c ratio are greater.

\section{Sodium chloride penetration}

Chloride ion penetration depths of water cured samples are presented in Figure 4. Figure 4(a) indicates that for a given w/c ratio, the chloride penetration depth for APC samples is somewhat lower than that of OPC samples, but greater than HVFA samples. Chloride ions penetrate into samples through different mechanisms, namely capillary absorption of chloride containing liquids, permeation of $\mathrm{NaCl}$ solution, diffusion of free chloride ions and ion exchange between $\mathrm{Cl}^{-}$and $\mathrm{OH}^{-}$ions (Hilsdorf \& Kropp, 1995). In the case of dry samples, capillary absorption and permeation would be the major mechanisms; however, in the case of water cured samples where the pore structure is filled with water, ion exchange and diffusion would dominate. Chloride ion penetration through ion exchange depends on the quantity of $\mathrm{OH}^{-}$ions in the pore water, which in turn depends on the availability of free $\mathrm{Ca}(\mathrm{OH})_{2}$. OPC samples have a large quantity of $\mathrm{Ca}(\mathrm{OH})$, released during the hydration process. APC specimens also have $\mathrm{Ca}(\mathrm{OH})_{2}$ released from the $30 \%$ OPC and the added lime. However, a significant part of the $\mathrm{Ca}(\mathrm{OH})_{2}$, would be used up in the pozzolanic reaction with fly ash. HVFA comprises only $30 \%$ OPC and $70 \%$ fly ash, and the $\mathrm{Ca}(\mathrm{OH})_{2}$ released during OPC hydration would be largely consumed in reactions with fly ash. Hence free $\mathrm{Ca}(\mathrm{OH})_{2}$, would either be very low or non-existent in HVFA samples. Thus, free
$\mathrm{Ca}(\mathrm{OH})_{2}$ in HVFA samples would be less than in APC, which in turn would be less than in OPC samples. This explains the reason for decrease of chloride penetration through ion exchange from OPC through APC to HVFA. However, since specimen porosity would increase from OPC through APC to HVFA, diffusion processes would also increase in the same sequence. It appears however, that the differences in ion-exchange processes govern the chloride ion penetration here. Therefore, the resistance to chloride ion penetration of water-cured APC samples is somewhat better than that of OPC, but less than that of HVFA samples. It should be noted that the strength development of specimens immersed in artificial seawater over 90 days was found to be slightly better for hybrid cements compared to OPC (Fernandez-Jimenez et al., 2013) and to sulphate resistant cement (Donatello et al., 2013). Although strength change due to immersion was not measured by us, the Fernandez-Jimenez et al. (2013) results can be seen as complementing the present findings on immersion depths.

Chloride penetration depths for different APC mixtures L, M and $\mathrm{N}$ are depicted in Figure 4(b). The chloride penetration decreases from mixture $\mathrm{L}$ through $\mathrm{M}$ to $\mathrm{N}$. In these APC mixtures the proportion of fly ash increases from mixture $\mathrm{L}$ through $\mathrm{M}$ to $\mathrm{N}$, and the complementary portion of lime decreases. This means that the amount of unreacted $\mathrm{Ca}(\mathrm{OH})_{2}$, will decrease from mixture L through $\mathrm{M}$ to $\mathrm{N}$. As the quantity of unreacted $\mathrm{Ca}(\mathrm{OH})_{2}$ decreases, chloride penetration through ionexchange also decreases.

The other obvious feature in Figures 4(a) and (b) is that penetration depth is higher in specimens with $\mathrm{w} / \mathrm{c}=0.4$ than in those with $\mathrm{w} / \mathrm{c}=0.3$. This is because the porosity increases at the higher $\mathrm{w} / \mathrm{c}$ ratio, resulting in greater diffusion and ion exchange.

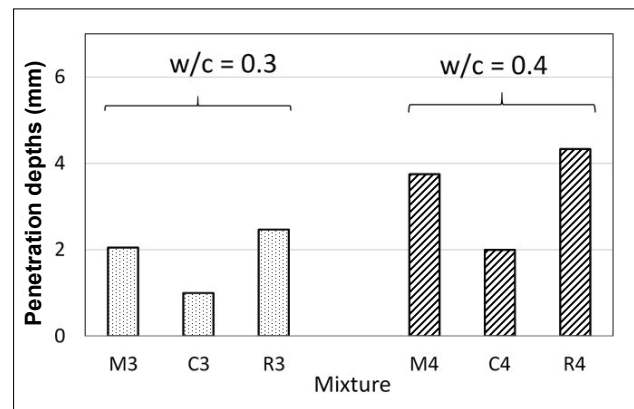

(a) Chloride ion penetration: M-C-R grouping

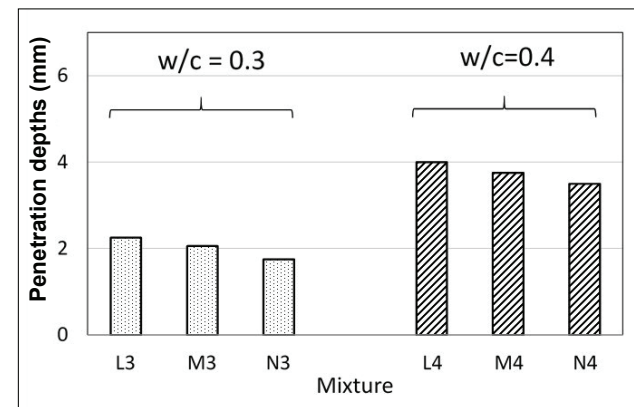

(b) Chloride ion penetration: L-M-N grouping

Figure 4: Chloride penetration depths 
Sensitivity indices of the mixtures are as follows: L-0.78, M-0.82, N-1.00, C-1.00 and R-0.75. Thus, the sensitivity of APC mixture M is similar to that of OPC but less than that of HVFA mixture $\mathrm{C}$; i.e., the robustness of APC and OPC are similar and better than that of HVFA. Among APC mixtures, mixture $\mathrm{N}$ has the greatest sensitivity; i.e. the robustness of mixtures $\mathrm{L}$ and $\mathrm{M}$ are similar and better than that of $\mathrm{N}$. Both mixtures $\mathrm{C}$ and $\mathrm{N}$ (that display the highest sensitivity) contain $30 \%$ of OPC. Mixture N has the least amount of added lime among APC mixtures, and mixture $\mathrm{C}$ does not have any added lime. Hence, in these mixtures, the quantity of $\mathrm{Ca}(\mathrm{OH})_{2}$ would be less than in others and water consumed for pozzolanic reactions would also be less. Therefore, a greater part of the excess water would increase the porosity in the samples rather than contributing to hydration. As a result, sensitivity to $\mathrm{w} / \mathrm{c}$ ratio in those samples becomes relatively higher.

\section{Carbonation}

Since the samples used were $50 \mathrm{~mm}$ cubes, when carbonation depths of two opposite sides reach $25 \mathrm{~mm}$, the whole specimen gets fully carbonated. Hence, carbonation depths could be determined only up to $25 \mathrm{~mm}$. Carbonation depths of air cured samples for different mixtures are presented in Figure 5. In this figure, carbonation depths of samples made with w/c of 0.3 and 0.4 from a particular mixture are coupled together, while carbonation depths at 1 month and 3 month exposure are grouped and presented separately. The fully carbonated depth (i.e. $25 \mathrm{~mm}$ depth) is indicated by the broken line.

According to Figure 5, none of the samples were fully carbonated in 1 month. However, by 3 months, samples of the HVFA mixture $\mathrm{C}$ got fully carbonated. APC mixture $\mathrm{N}$ prepared with $\mathrm{w} / \mathrm{c}=0.4$ also got almost fully carbonated. Figure 5(a) indicates that for a given $\mathrm{w} / \mathrm{c}$ ratio $(0.3$ or 0.4$)$ and at a given duration of exposure (1 month or 3 months), carbonation depths decrease from HVFA through APC to OPC. Carbonation depends on the porosity of samples and the quantity of free $\mathrm{Ca}(\mathrm{OH})_{2}$ available. If the porosity is high, $\mathrm{CO}_{2}$ penetrates into the sample easily; and if the free $\mathrm{Ca}(\mathrm{OH})_{2}$ available is less, it is carbonated more quickly. The porosity decreases from HVFA through APC to OPC. The quantity of free $\mathrm{Ca}(\mathrm{OH})_{2}$ also increases from HVFA through APC to OPC, as explained before. Thus, the limited $\mathrm{Ca}(\mathrm{OH})_{2}$ in the more porous HVFA samples gets carbonated quickly. In the case of the least porous OPC, it takes a longer time for $\mathrm{CO}_{2}$ to penetrate and carbonate the relatively large quantity of $\mathrm{Ca}(\mathrm{OH})_{2}$. Conditions in APC fall in between
HVFA and OPC; hence the carbonation results also reflect a median position for APC. Thus, resistance to carbonation decreases from OPC through APC to HVFA.

Figure 5(b) presents the carbonation depths of different APC mixtures L, M and N. For a given w/c ratio ( 0.3 or 0.4 ), and at a given duration of exposure (1 month or 3 months), carbonation depth increases from mixture L through $\mathrm{M}$ to $\mathrm{N}$. Among APC mixtures the added lime decreases from mixture $\mathrm{L}$ through $\mathrm{M}$ to $\mathrm{N}$ and the fly ash quantity increases in the same sequence. Hence, the free $\mathrm{Ca}(\mathrm{OH})_{2}$ content will also decrease from mixture $\mathrm{L}$ through $\mathrm{M}$ to $\mathrm{N}$ since lime in the mixture is consumed in reactions with fly ash. Thus, resistance to carbonation decreases from mixture $\mathrm{L}$ through $\mathrm{M}$ to $\mathrm{N}$.

The other obvious feature in Figures 5(a) and (b) is that for a particular mixture at a given duration of exposure (1 month or 3 months), carbonation depth is higher in specimens of $\mathrm{w} / \mathrm{c}=0.4$ than in those of 0.3 , because of the greater porosity in the former. The ratios between carbonation depths at 3 to 1 month of exposure for mixtures L3, L4, M3, M4, N3, N4, R3 and R4 were obtained as 1.6, 1.8, 1.5, 2.0, 1.7, 1.9, 1.8 and 1.9 , respectively. It is seen that the ratio falls between 1.5 and 2.0 for all the mixtures, and is generally close to 1.7 , i.e. $(3 / 1)^{0.5}$. This endorses the square root of time model for carbonation rate (Bijen, 2003; Grantham et al., 2009) and also increases confidence in our experimental techniques.

Sensitivity indices of the mixtures at 1 month of exposure are as follows: L-0.83, M-1.02, N-0.58, C-0.46 and R-0.07. At 3 months, the sensitivity index for mixture $\mathrm{C}$ cannot be determined as samples were fully carbonated. The sensitivity indices for other mixtures are: L -1.08, M-1.66, N-0.79 and R-0.13. It can be said that the sensitivities of APC mixture $\mathrm{M}$ and HVFA mixture $\mathrm{C}$ are greater than that of OPC mixture $\mathrm{R}$. Thus, the robustness of OPC is greater than that of HVFA and APC. The sensitivities of APC mixtures L, M and $\mathrm{N}$ do not portray a monotonic order; the middle mixture $\mathrm{M}$ has the greatest sensitivity. The sensitivity to $\mathrm{w} / \mathrm{c}$ ratio is greater at 3 months than at 1 month in all mixtures. Initially, all samples have higher quantities of free $\mathrm{Ca}(\mathrm{OH})_{2}$. However over time, free $\mathrm{Ca}(\mathrm{OH})_{2}$ decreases due to the carbonation process and also due to pozzolanic reactions (in APC and HVFA samples). Thus, the remaining limited $\mathrm{Ca}(\mathrm{OH})_{2}$ gets carbonated faster in more porous samples $(\mathrm{w} / \mathrm{c}=0.4)$ than in less porous samples $(\mathrm{w} / \mathrm{c}=0.3)$. 

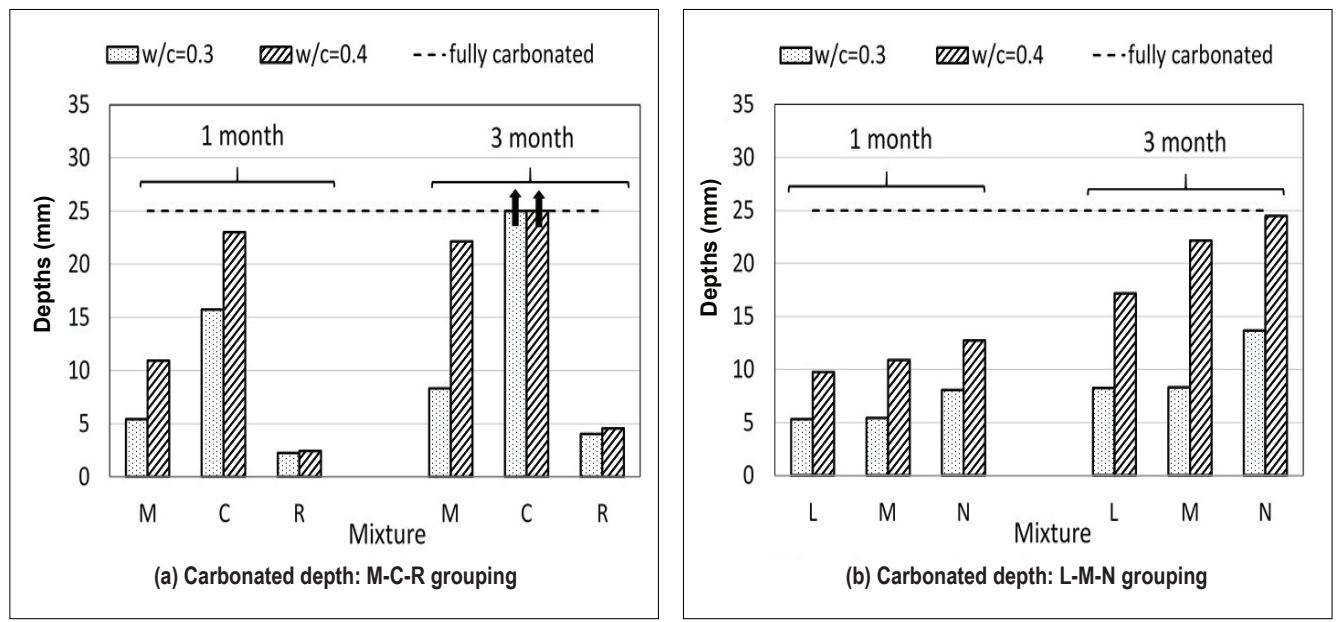

Figure 5: Carbonation depths of all mixtures at 1 month and 3 months

Table 2: Performance and robustness of various mixtures

\begin{tabular}{lll}
\hline Durability test & Performance (resistance) & Robustness to w/c change \\
\hline Water absorption & OPC $>$ APC $>$ HVFA & APC $>$ OPC $\approx$ HVFA \\
Sulphuric acid attack & HVFA $>$ APC $>$ OPC & Not relevant \\
Chloride ion penetration & HVFA $>$ APC $>$ OPC & OPC $\approx$ APC $>$ HVFA \\
Carbonation & OPC $>$ APC $>$ HVFA & OPC $>$ APC $\approx$ HVFA \\
\hline
\end{tabular}

\section{Comparison of mixtures}

Durability properties of APC mixtures in comparison to HVFA and OPC mixtures were investigated through water absorption of 28-day-old samples; and through sulphuric acid attack, sodium chloride ion penetration and carbonation in 1-year-old samples. The robustness of these properties when increasing the $\mathrm{w} / \mathrm{c}$ ratio from 0.3 to 0.4 was also investigated. Table 2 summarises the key findings, focusing on the M-C-R grouping, since differences among the L-M-N grouping were not as significant. The robustness for the sulphuric acid test is not reported, since increases in $\mathrm{w} / \mathrm{c}$ ratio are beneficial for this test.

It can be seen in the foregoing discussion that the $\mathrm{Ca}(\mathrm{OH})_{2}$ content influences all the chemical attack related durability properties. Thermogravimetric analysis conducted in the course of this research (Kulasuriya, 2015), and which will be reported in detail in a subsequent paper, indicated that the $\mathrm{Ca}(\mathrm{OH})_{2}$ content decreased monotonically from 3 to 112 days for M3 and C3 (at a faster rate for M3), and increased for R3. This confirms the assertions that were used in the preceding discussions regarding the amounts (and changes in those amounts) of $\mathrm{Ca}(\mathrm{OH})_{2}$ to explain the chemical attack test results. It was observed that APC occupies a median position with respect to both durability and robustness to $\mathrm{w} / \mathrm{c}$ changes. It is interesting that the strength results in Table 1 for the M-C-R grouping also indicate that OPC $>$ APC $>$ HVFA. In other words, whether for strength or the durability properties tested, APC occupies the median position. This is promising for this newly developed hybrid cement, which has potential for reducing OPC usage, while displaying acceptable engineering properties.

\section{CONCLUSIONS}

Based on the experimental results presented in this paper, the following overall conclusions can be drawn:

OPC offers greater resistance against water absorption and carbonation, while HVFA does so against sulphuric acid attack and chloride ion penetration. APC occupies the median position for durability aspects. Even where 
robustness to increases in w/c ratio is concerned, APC secures such a median position in general.

Where APC mixtures L, M and $\mathrm{N}$ are concerned, the performance and robustness of mixtures are similar, although $\mathrm{L}$ or $\mathrm{N}$ are slightly better in certain aspects, with the APC mixture M again taking the median position.

The amounts (and changes in those amounts) of $\mathrm{Ca}(\mathrm{OH})_{2}$ significantly influence the durability properties with respect to water absorption, sulphuric acid attack, sodium chloride penetration and carbonation; especially resistance to sulphuric acid attack and carbonation.

These durability test results are promising for the newly developed alkali pozzolan cement (APC), because it demonstrates the ability to perform in a general purpose fashion, without being particularly badly affected by any one of the common durability issues. The best formulation of APC is probably the one using APC70, because it performs reasonably well across all the tests.

\section{Acknowledgement}

The authors wish to thank the present and former Technical Managers of the Civil Engineering Laboratories at Curtin University, Perth, Australia, Mick Ellis and Ashley Hughes and their teams, for their assistance in conducting experiments.

\section{REFERENCES}

ASTM C140 (2002). Standard Test Methods for Sampling and Testing Concrete Masonry Units and Related Units. American Society for Testing and Materials (ASTM) International, Pennsylvania, USA.

ASTM C267 (2012). Standard Test Methods for Chemical Resistance of Mortars, Grouts, and Monolithic Surfacings and Polymer Concretes. American Society for Testing and Materials (ASTM) International, Pennsylvania, USA.

Atiş C.D. (2003). Accelerated carbonation and testing of concrete made with fly ash. Construction and Building Materials 17(3): 147-152.

DOI: https://doi.org/10.1016/S0950-0618(02)00116-2

Attiogbe E.K. \& Rizkalla S.H. (1988). Response of concrete to sulfuric acid attack. ACI Materials Journal 85(6): 481-488.

Bije J. (2003). Durability of Engineering Structures: Design, Repair and Maintenance. Woodhead Publishing Ltd., Cambridge, UK.

Dias W.P.S. (2000). Reduction of concrete sorptivity with age through carbonation. Cement and Concrete Research 30(8): 1255-1261.

DOI: https://doi.org/10.1016/S0008-8846(00)00311-2
Dias W.P.S., Seneviratne G.A.P.S.N. \& Nanayakkara S.M.A. (2008). Offshore sand for reinforced concrete. Construction and Building Materials 22(7): 1377-1384.

DOI: https://doi.org/10.1016/j.conbuildmat.2007.04.006

Donatello S., Garcia-Lodeiro I., Fernandez-Jimenez A. \& Palomo A. (2014). Some Durability Aspects of Hybrid Alkaline Cements. MATEC Web of Conferences 11: 01008. DOI: https://doi.org/10.1051/matecconf/20141101008

Donatello S., Palomo A. \& Fernandez-Jimenez A. (2013). Durability of very high volume fly ash cement pastes and mortars in aggressive solutions. Cement and Concrete Composites 38: 12-20.

DOI: https://doi.org/10.1016/j.cemconcomp.2013.03.001

Fernandez-Jimenez A., Flores, E., Maltseva O., Garcia-Lodeiro I. \& Palomo A. (2013). Cimenturi hibride alcaline cements. part III. Durability and industrial applications. Revista Română de Materiale/Romanian Journal of Materials 43(2): 195-200.

Ghrici M., Kenai S. \& Said-Mansour M. (2007). Mechanical properties and durability of mortar and concrete containing natural pozzolana and limestone blended cements. Cement and Concrete Composites 29(7): 542-549.

DOI: https://doi.org/10.1016/j.cemconcomp.2007.04.009

Gonen T. \& Yazicioglu S. (2007). The influence of compaction pores on sorptivity and carbonation of concrete. Construction and Building Materials 21(5): 1040-1045. DOI: https://doi.org/10.1016/j.conbuildmat.2006.02.010

Grantham M., Majorana C. \& Salomoni V. (2009). Concrete Solutions. CRC Press, Boca Raton, USA. DOI: https://doi.org/10.1201/9780203864005

Hilsdorf H. \& Kropp J. (1995). Performance Criteria for Concrete Durability. E. \& F.N. Spon Ltd., London, UK.

Kulasuriya C., Vimonsatit V., Dias W.P.S. \& De Silva P. (2014). Design and development of alkali pozzolan cement (APC). Construction and Building Materials 68: 426-433. DOI: https://doi.org/10.1016/j.conbuildmat.2014.06.095

Kulasuriya C. (2015). Alkali pozzolan cement for integral sustainability. PhD thesis, Curtin University, Perth, Australia.

Mondal B., Uddin N. \& Amin I. (2011). A study on sulfuric acid attack on cement mortar with rice husk ash, $4^{\text {th }}$ Annual Paper Meet and 1st Civil Engineering Congress, Dhaka, Bangladesh, December 22-24, pp. 44-49.

Monteny J., Vincke E., Beeldens A., De Belie N., Taerwe L., Van Gemert D. \& Verstraete W. (2000). Chemical, microbiological, and in situ test methods for biogenic sulfuric acid corrosion of concrete. Cement and Concrete Research 30(4): 623-634.

DOI: https://doi.org/10.1016/S0008-8846(00)00219-2

O'Connell M., McNally C. \& Richardson M.G. (2010). Biochemical attack on concrete in wastewater applications: a state of the art review. Cement and Concrete Composites 32(7): 479-485.

DOI: https://doi.org/10.1016/j.cemconcomp.2010.05.001

Otsuki N., Nagataki S. \& Nakashita K. (1993). Evaluation of the $\mathrm{AgNO}_{3}$ solution spray method for measurement of chloride 
penetration into hardened cementitious matrix materials. Construction and Building Materials 7(4): 195-201. DOI: https://doi.org/10.1016/0950-0618(93)90002-T

Pipilikaki P. \& Katsioti M. (2009). Study of the hydration process of quaternary blended cements and durability of the produced mortars and concretes. Construction and Building Materials 23(6): 2246-2250.

DOI: https://doi.org/10.1016/j.conbuildmat.2008.11.015

Qian J., Shi C. \& Wang Z. (2001). Activation of blended cements containing fly ash. Cement and Concrete Research
31(8): 1121-1127.

DOI: https://doi.org/10.1016/S0008-8846(01)00526-9

Ryan M. (1999). Sulphate Attack and Chloride Ion Penetration: Their Role in Concrete Durability. QCL Group Technical Report. QCL Group, Australia.

Standards Australia AS 3972 (2010). General Purpose and Blended Cements. Standards Australia, Sydney.

Wallah S. \& Rangan B.V. (2006). Low-calcium fly ash-based geopolymer concrete: long-term properties. Resarch Report-GC2, pp, 76-80. Curtin University, Australia. 